\title{
Labyrinth Seal Design Optimization Based on Quadratic Regression Orthogonal Experiment
}

\author{
Lihua Cao, Heyong Si, Pan Li, Yong Li \\ School of Energy and Power Engineering, Northeast Electric Power University, Jilin, China \\ Email: clh320@163.com
}

How to cite this paper: Cao, L.H., Si, H.Y., Li, P. and Li, Y. (2017) Labyrinth Seal Design Optimization Based on Quadratic Regression Orthogonal Experiment. Energy and Power Engineering, 9, 204-215. https://doi.org/10.4236/epe.2017.94B025

Received: February 23, 2017

Accepted: March 30, 2017

Published: April 6, 2017

\begin{abstract}
The influence of labyrinth seal structure parameters and their interaction on the characteristics of leakage amount are numerically investigated by conducting a quadratic regression orthogonal experiment. To determine the optimal structure parameters of the steam seal for minimizing the leakage amount, a reliable regression equation that does not lack of fit is established. The flow characteristics of the fluid in the labyrinth seal are analyzed in detail. Results show that the leakage amount is greatly influenced by seal cavity depth, convex platform height, seal tooth thickness, and tooth tip clearance, with the tip clearance having the most significant effect. The interaction among the four items exerts a certain impact on the leakage amount. The proposed regression equation exhibits a good significance and does not lack of fit. After optimization, the labyrinth seal demonstrates increased entropy and energy dissipation at the tip of the seal tooth, as well as decreased speed and inertia effect in the cavity, suggesting that the resistance leakage performance of the optimized labyrinth seal is improved.
\end{abstract}

\section{Keywords}

Labyrinth Seal, Structure Parameters, Regression Orthogonal Test, Leakage Amount, Optimization

\section{Introduction}

The diaphragm seal of steam turbine plays an important role in preventing steam leakage and reducing steam turbine loss. The diaphragm seal is widely used because of its simple structure, convenient installation, and high efficiency [1] [2] [3]. Labyrinth seals have various kinds, and different factors affect their efficiency. Studies on the leakage characteristics of the labyrinth, rub-groove labyrinth, radial annular seal, and honeycomb labyrinth seals have demonstrated that the leakage amount positively changes with the pressure ratio [4] [5] [6]. 
When all other conditions are constant, the rotor speed, in contrast to the seal structure, has a negligible effect on the leakage amount [7] [8] [9]. The less is the number of labyrinth seals, the greater is the leakage amount because of the number of steam seal teeth; moreover, the leakage amount increases with an increase in seal tip clearance [10] [11]. On this basis, a researcher pointed out that the leakage coefficient is linear to the sealing tip clearance [12]. A qualitative analysis using carbon dioxide as working fluid was conducted on the relationships among labyrinth seal leakage, tooth tip clearance, cavity width, cavity depth, and so on; the findings revealed that the leakage amount increased with an increase in tooth tip clearance, decreased with an increase in cavity width, and initially decreased and subsequently increased with an increase in cavity depth [13]. Several domestic scholars have posited that different types of seal have different flow field characteristics and leakage amounts; these studies found a trend that the leakage amount increased with an increase of cavity depth, and decreased with an increase in the thickness of the seal teeth [14]. However, a research on the high-pressure labyrinth seal of the $\mathrm{F}$ gas turbine found that the leakage coefficient decreased with a decrease in the thickness of the seal teeth [15]. Analyzing the changes in sealing tooth top pressure and turbulent kinetic energy is one of the ways to study the sealed effect and the influence of different tooth structures on the leakage amount [16].

Many studies have investigated the influence of labyrinth seal structure parameters on the leakage amount, and reliable conclusions have been obtained. However, most of these studies were conducted by controlling a single variable factor. Choosing an appropriate research method is one of the important steps in analyzing sealing leakage characteristics. Orthogonal experiments have been widely used in biology, engineering, and other fields to study the effects of multiple factors on the test index [17] [18] [19]. The regression orthogonal experiment is based on the orthogonal experiment to establish a regression equation and implement a series of verification and analysis. This experiment has a high superiority in the study of quantitative relationship between multi-factors and the test index [20] [21].

Therefore, a regression equation is established in this paper by using quaternion quadratic regression orthogonal experiment to analyze the effects of multiple structure parameters on the leakage amount in consideration of the notion that basic geometrical parameters of the labyrinth seal have different influences on leakage characteristics. In addition, the solution of the regression equation is calculated by programming to confirm the optimal structure parameters that correspond to maximum sealing efficiency.

\section{Regression Orthogonal Experiment}

\subsection{Numerical Calculation Method}

The cavity depth, convex platform height, tooth thickness, and tooth tip clearance parameters of a $300 \mathrm{MW}$ condensing steam turbine are quoted according to the actual labyrinth seal structure parameters to identify the variation range of 
factors in regression orthogonal experiment that ensures the availability and reliability of the experiment in engineering. The concrete structure parameters are shown in Figure 1.

Calculation time is reduced by using an arc section with a periodic surface rotated 3.6 degrees around the center rather than the whole cycle section. Under the same grid number, the model has a higher grid quality.

In the calculation, water vapor is set in accordance with the real condition, which pressure boundary conditions are adopted in the inlet and outlet of the calculation domain. The pressure and temperature in the inlet is $10.7 \mathrm{MPa}$ and $744.25 \mathrm{~K}$, whereas that at the outlet is $10.263 \mathrm{MPa}$ and $734.25 \mathrm{~K}$. Standard $\mathrm{k}-\varepsilon$ equation is combined with SIMPLE algorithm in the $3 \mathrm{D}$ flow field of the labyrinth seal to solve the N-S equation. Gambit software is used to model the arc section, and the grid has a negligible effect on the calculation results of the steam leakage when the grid spacing reaches $0.05-0.1$ and the grid number exceeds 2 million, as shown in Figure 2. The y plus is 35 to ensure that the turbulence model has higher accuracy. Therefore, the number of mesh used in this paper is

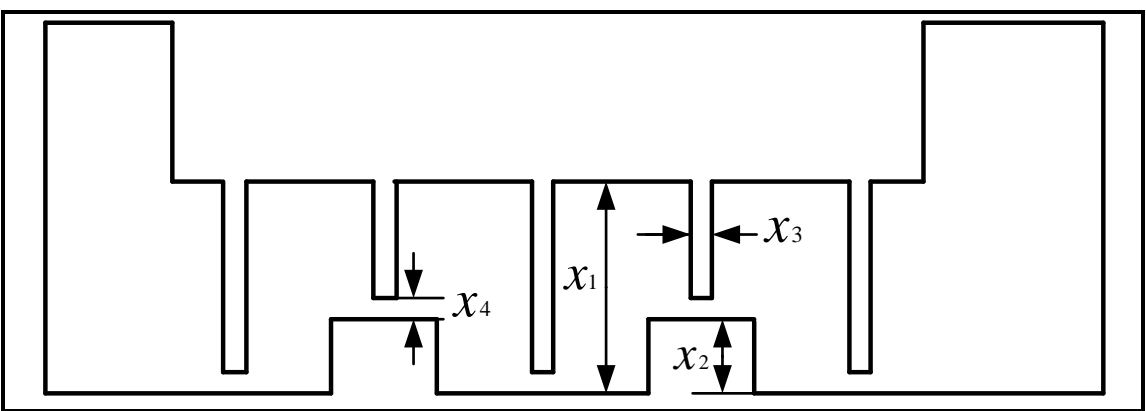

Figure 1. Schematic diagram of labyrinth seal structure.

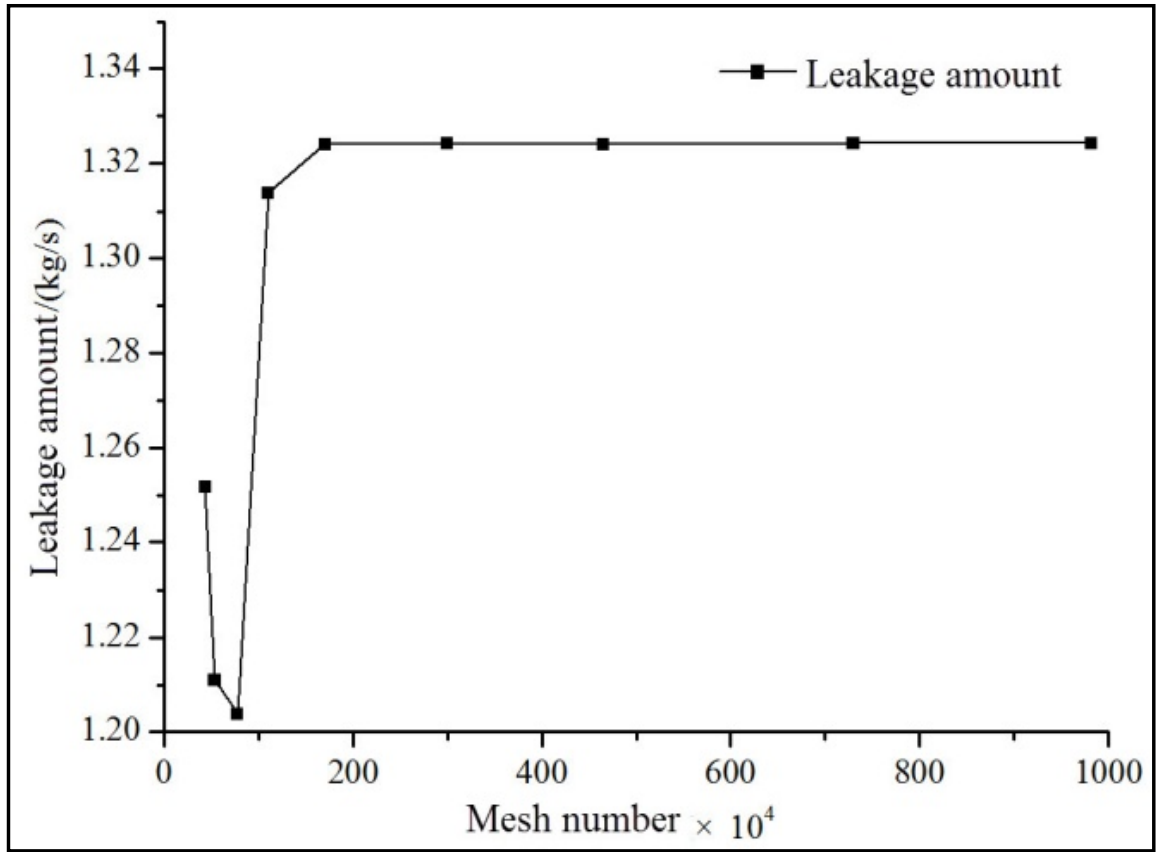

Figure 2. The leakage quantity varies with the number of grid cells. 
on the range of 200 - 300 million to improve the calculation speed.

\subsection{Design of the Regression Orthogonal Experiment}

Regression orthogonal experiment is chosen to arrange the simulated calculation statistics in a reasonable range of factors, and a regression equation with a certain degree of confidence is established by using finite experiment points. Consequently, the leakage amount can be estimated by using the regression equation when the structure parameters are determined, and the theoretical optimum value of test factors that corresponds to the minimum leakage amount of steam can be obtained in a certain range by solving the regression equation. Such an approach avoids a great deal of computation, reduces the testing workload, and improves the efficiency of the labyrinth seal design optimization.

Therefore, this paper uses the quaternion quadratic regression orthogonal $1 / 2$ implementation method and determines the variation range of four control parameters on the basis of the general principles of labyrinth seal design: the cavity depth $x_{1}$ is $5-13 \mathrm{~mm}$; the convex platform height $x_{2}$ is $1.5-4.5 \mathrm{~mm}$; the tooth thickness $x_{3}$ is $0.2-1.6 \mathrm{~mm}$; the tooth tip clearance $x_{4}$ is $0.2-1 \mathrm{~mm}$. If $x_{j}(\mathrm{j}=1,2$, $3,4)$ is the level of each factor in the regression orthogonal experiment, and $x_{1 j}$ and $x_{2 j}$ are upper and lower limits of the factors, then the zero level of the factor can be represented by $x_{0 j}=\left(x_{1 j}+x_{2 j}\right) / 2$. Based on the variation range of the factors, the level code is as shown in Table 1.

The number of numerical calculations of the experiment program is determined by Equation (1), which, compared with a comprehensive experiment with five levels and four factors (i.e., $5^{4}=625$ times), only needs 17 times. The calculation period is reduced to $2.72 \%$ of the original one.

$$
n=m_{0}+m_{c}+m_{r}
$$

where $m_{0}$, the center tests' number, is $1 ; m_{c}$, the times of two level test, is $2 \mathrm{p}-1$; $m_{r}$, the asterisk test, is $2 \mathrm{p}$; $\mathrm{p}$, the number of factors, is 4 ; $r$, the asterisk arm length, is $r=\left(\sqrt{n m_{c}}-m_{c}\right)^{1 / 2} / \sqrt{2} \quad$ (i.e., $\left.r=1.353\right)$.

The change step of the test level can be determined by the upper and lower limits of the factors and asterisk arm length.

$$
\Delta_{j}=\frac{x_{1 j}-x_{2 j}}{2 r}
$$

\begin{tabular}{|c|c|c|c|c|}
\hline Levels Factors & $\begin{array}{c}\text { cavity depth } \\
x_{1} / \mathrm{mm}\end{array}$ & $\begin{array}{l}\text { convex platform height } \\
\qquad x_{2} / \mathrm{mm}\end{array}$ & $\begin{array}{c}\text { tooth thickness } \\
x_{3} / \mathrm{mm}\end{array}$ & $\begin{array}{c}\text { tooth tip clearance } \\
\qquad x_{4} / \mathrm{mm}\end{array}$ \\
\hline$(+r)$ & 13 & 4.5 & 1.6 & 1 \\
\hline$(+1)$ & 12 & 4 & 1.4 & 0.9 \\
\hline (0) & 9 & 3 & 0.9 & 0.6 \\
\hline$(-1)$ & 6 & 2 & 0.4 & 0.3 \\
\hline$(-r)$ & 5 & 1.5 & 0.2 & 0.2 \\
\hline$\Delta_{j}$ & 3 & 1 & 0.5 & 0.3 \\
\hline
\end{tabular}

Table 1. Encode form of two levels and four factors. 
The factors should be kept in a consistent dimension and should not substantially differ in the orthogonal experiment. Thus, the natural variables of each factor should be treated in the centralization. Suppose $Z_{j}$ is code value obtained after the centralization of each factor level value, then $z_{j}=\left(x_{j}+x_{0 j}\right) / \Delta_{j}$. The test results and analysis are presented in Table 2.

A unified form of regression equation can be obtained by the data processing of the orthogonal table:

$$
S=\sum_{j=1}^{n} y_{j}^{2}-\frac{1}{n}\left(\sum_{j=1}^{n} y_{j}\right)^{2}
$$

Here, $y$ denotes the steam leakage amount, which is the inspection index of the test object. Given that the leakage amount of the partial arc section of the labyrinth seal model is small, the steam leakage of that arc section is converted to a leakage of the whole cycle section; i.e., the leakage is magnified one hundred times. $b$ is a constant term. $b_{j}$ is the first regression coefficient. $b_{i j}$ is the partial regression coefficient of the interaction term. $b_{j j}$ is the quadratic regression coefficient.

Table 2. Analysis of results of regression orthogonal experiments.

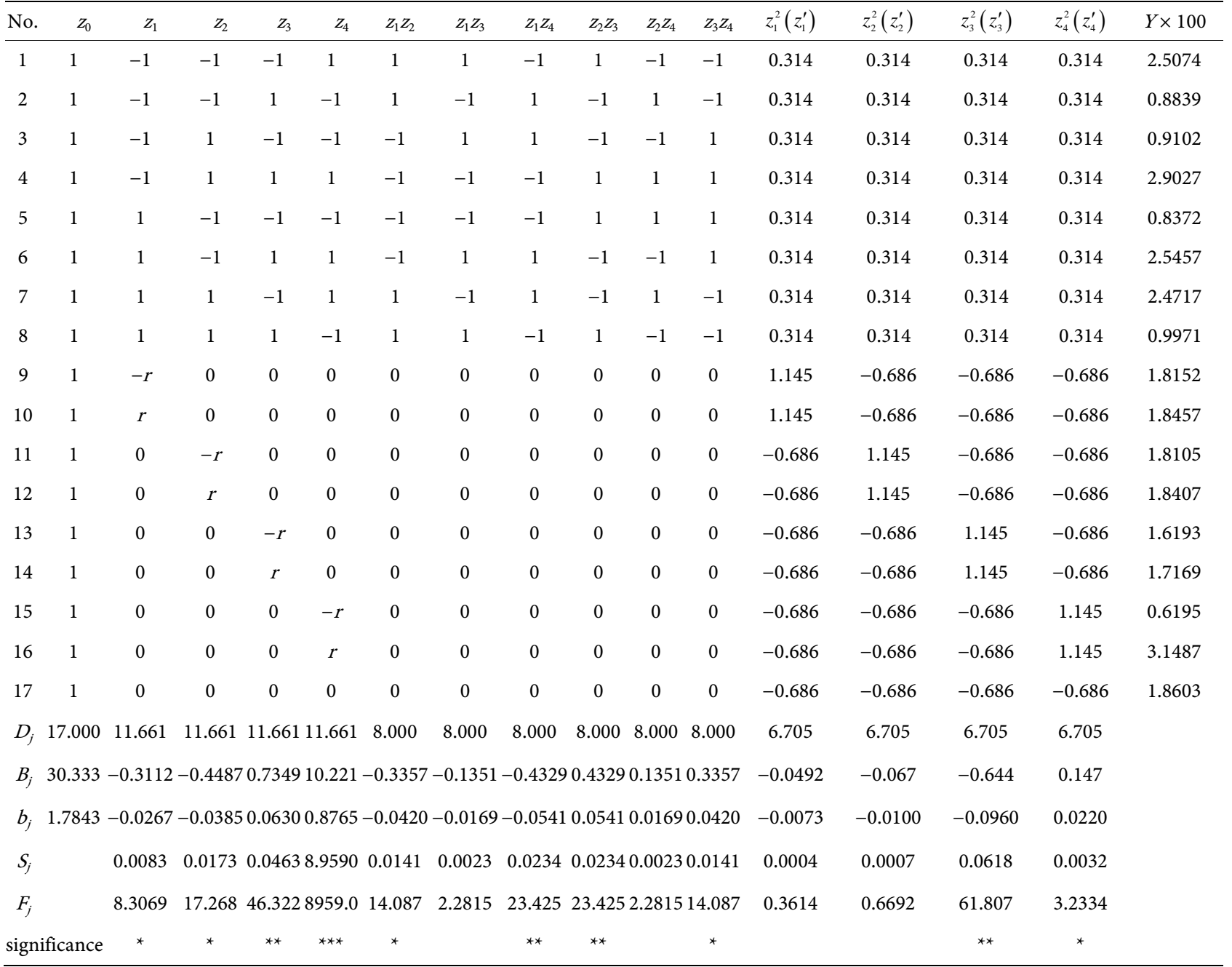


According to the above coefficients and the data in the table, the specific calculation equation can be expressed as follows:

$$
D_{j}=\sum_{j=1}^{n}\left(z_{i j}\right)^{2}, B_{j}=\sum_{j=1}^{n} z_{i j} y_{j}, b_{i}=\frac{B_{j}}{D_{j}}, S_{j}=B_{j} b_{j}, F_{j}=\frac{S_{j} / f_{j}}{S_{e} / f_{e}}
$$

where $f_{j}=1 . S_{e}$ is the error sum of squares, which is obtained by $S_{e}=\sum_{j=1}^{m_{0}}\left(\mathrm{y}_{j 0}-\bar{y}_{j 0}\right)^{2}$.

To conduct the significant test and the lack of fit test of the regression equation, three center experiments are conducted in this paper. The error sum of squares $S_{e}$ is 0.002 , and its degree of freedom $f_{e}$ is 2 , when $y_{j 0}$ are 1.8603, 1.8442 , and 1.801. The coefficients of the regression equation are determined by the test of the regression coefficient of the orthogonal experiment. And the factors that correspond to the coefficient significantly affect $y$ if $F_{j}>F_{0.25}\left(f_{j}, f_{e}\right)$. In Table 2, "*»" indicates that the significance of the level satisfies $F_{0.25}\left(f_{j}, f_{e}\right)$; i.e., the confidence level reached 0.25. Similarly, " $* *$ " indicates that the significance of the level satisfies $F_{0.05}\left(f_{j}, f_{e}\right)$, and “ $* * *$ " indicates that the significance of the level satisfies $F_{0.01}\left(f_{j}, f_{e}\right)$. In this study, all regression coefficients are significant except for $b_{13}, b_{24}, b_{11}$, and $b_{22}$, of which the level of satisfies $F_{j}<F_{0.25}\left(f_{j}, f_{e}\right)$. Taking insignificant regression terms in the remainder of the regression terms and obtaining the residual sum of squares is

$S_{R}=S-S_{h}=0.0109$, and the lack of fit square sum is $S_{l f}=S_{h}-S_{e}=0.0089$, where $S$ is total sum of squares and its formula is $S=\sum_{j=1}^{n} y_{j}^{2}-\frac{1}{n}\left(\sum_{j=1}^{n} y_{j}\right)^{2}$.

\subsection{Test of Significance and Not Lack of Fit of the Equation}

The influence of factors on the inspection index can be arranged in the values of $b_{j} b_{i j}$ and $b_{j j}$ by testing the regression coefficient of the equation. The array of linear terms is $z_{4}>z_{3}>z_{2}>z_{1}$. The array of interaction terms is

$z_{1} Z_{4}=z_{2} z_{3}>z_{3} z_{4} \cdot b_{4}$ is the largest, suggesting that $z_{4}$ has a very large effect on the leakage of steam, and the main factor that influences leakage in the steam turbine separator is the tooth tip clearance. Moreover, $b_{4}$ is positive, indicating that the steam leakage is smaller when the tooth tip clearance is smaller. This relationship is consistent with the theory that the flow area and the leakage is proportional to that derived from the empirical equation of steam leakage. In addition, cavity depth, convex platform height, tooth thickness, and their interaction exert certain effects on the leakage of steam. Positive regression coefficients indicate the positive correlation between the inspection index and the factors, whereas negative coefficients indicate the converse. The effects of the test terms on the inspection index are shown in Figure 3.

According to the significance test equation of the regression orthogonal experiment:

$$
\frac{S_{h} / f_{h}}{S_{R} / f_{R}}=504.826>F_{0.01}\left(f_{h}, f_{R}\right)=7.874
$$

The equation accords with the significance test of quaternion quadratic re- 


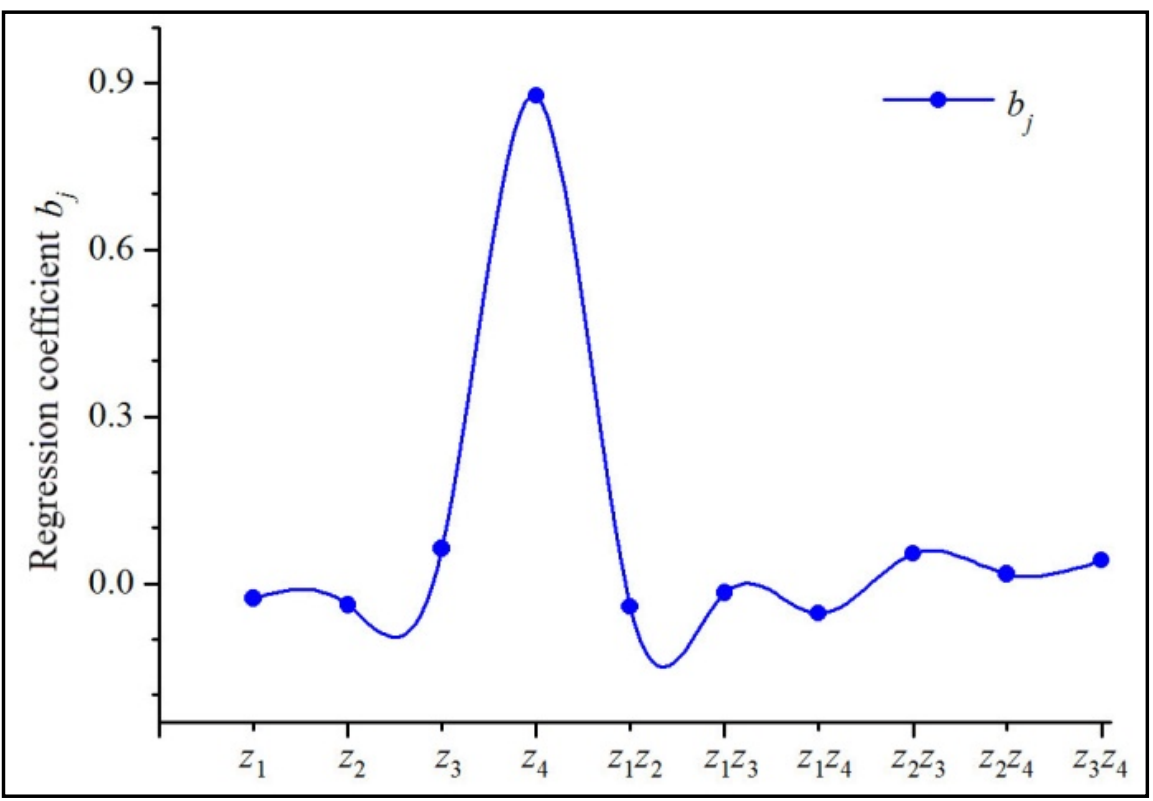

Figure 3. The variation of the regression coefficient of test items.

gression orthogonal experiment indicating that the confidence level of the regression equation is $(1-\alpha) \times 100 \%=99 \%$ and that the significance level is $\alpha=0.01$.

Similarly, according to the equation of the lack of fit:

$$
\frac{S_{l f} / f_{l f}}{S_{e} / f_{e}}=2.225<F_{0.25}\left(f_{l f}, f_{e}\right)=3.232
$$

The regression equation established in this paper can be determined to have good not lack of fit, indicating that the leakage, the linear term, the quadratic term, and the interaction of factors have a very good fit, and it has no significant relationship with higher-order terms.

\subsection{Transformation and Verification of the Regression Equation}

The regression equation can be obtained by the abovementioned method of calculation and data.

$$
\begin{aligned}
y= & 1.7843-0.0267 z_{1}-0.0385 z_{2}+0.063 z_{3}+0.8765 z_{4}-0.042 z_{1} z_{2} \\
& -0.0541 z_{1} z_{4}+0.0541 z_{2} z_{3}+0.042 z_{3} z_{4}-0.096 z_{3}^{2}+0.022 z_{4}^{2}
\end{aligned}
$$

In view of the verification test and the optimization design, the code of regression equations should be transformed into natural variables, and the test code is transformed inversely into the function of $x_{j}$ by the central processing equation:

$$
\begin{aligned}
y= & -0.368816+0.69166 x_{1}-0.00988 x_{2}+0.32464 x_{3} \\
& +2.91739 x_{4}-0.014 x_{1} x_{2}-0.06011 x_{1} x_{4}+0.1082 x_{2} x_{3} \\
& +0.28 x_{3} x_{4}-0.384 x_{3}^{2}+0.2444 x_{4}^{2}
\end{aligned}
$$

To verify the accuracy of the regression equation, the calculation of theoretical equation is implemented through a group of parameters in the reasonable range of each factor. When $x_{1}=9.5 \mathrm{~mm}, x_{2}=3.5 \mathrm{~mm}, x_{3}=0.7 \mathrm{~mm}$, and $x_{4}=0.5 \mathrm{~mm}$, 
the calculation result of the regression equation is $1.4246 \mathrm{~kg} / \mathrm{s}$, and the error is $6.14 \%$ than the result calculated by Fluent. These findings suggest that the equation has high accuracy and can meet the needs of engineering application to a certain extent.

\section{Results and Analysis of Optimal Design}

The regression Equation (7) is calculated by C\# under the constraints of a given range of factors and is locally optimized to determine the steam leakage. In this way, the best value that corresponds to the minimum value can be obtained for each factor to realize design optimization.

The calculated step size is set to 0.1 , and each factor $x_{j}$ is calculated to determine the minimum value of $y_{\min }$. Then, the program is improved to calculate $y_{\min }$ inversely, so that the corresponding natural factors in which the leakage is the minimum value can be determined. When $x_{1}=13 \mathrm{~mm}, x_{2}=4.5 \mathrm{~mm}$, $x_{3}=0.2 \mathrm{~mm}$, and $x_{4}=0.2 \mathrm{~mm}$, the minimum leakage of $y_{\min }$ is $0.26199 \mathrm{~kg} / \mathrm{s}$ after calculation, which is the optimal structure parameter in the range of each factor. At this point, the best structure ratio is $x_{1}: x_{2}: x_{3}: x_{4}=65: 22.5: 1: 1$.

Figure 4 shows the variation of pressure contours of tooth tip clearance in the

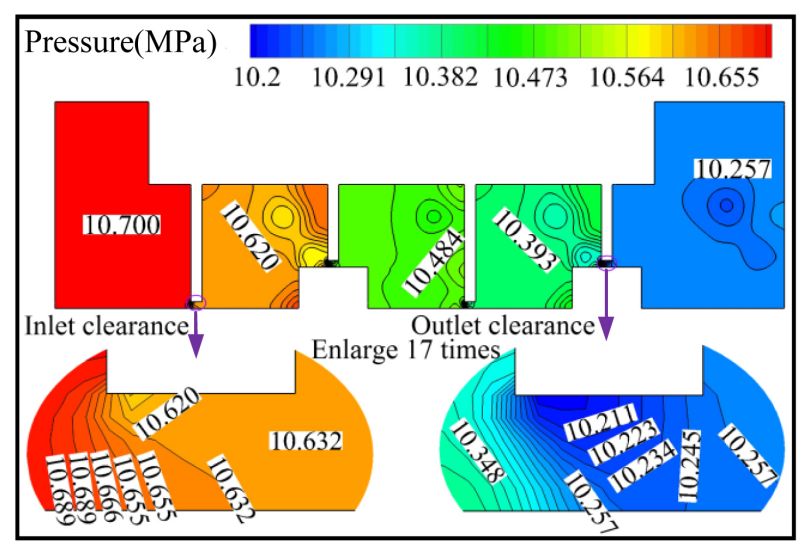

(a)

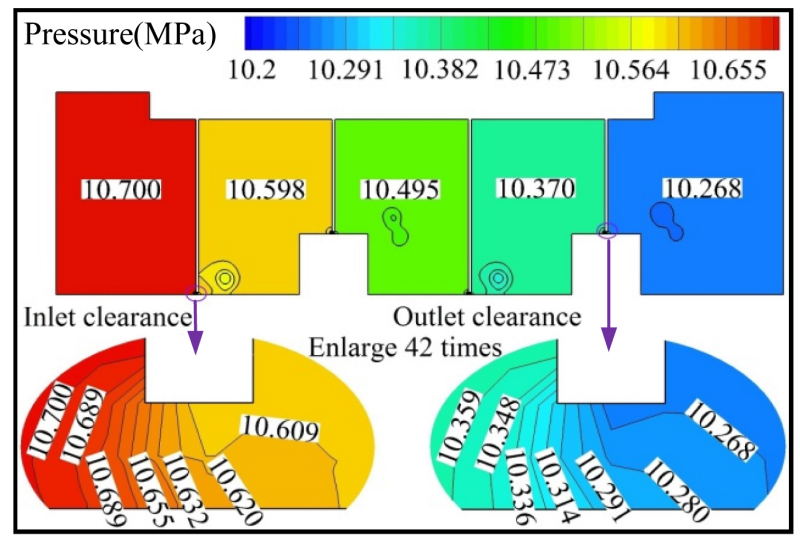

(b)

Figure 4. Pressure contours of flow field in the sealed cavities. (a) Before optimization; (b) After optimization. 
meridional plane before and after optimization. As shown in the diagram, the change in the pressure gradient mainly occurs at the top of the seal, showing that the kinetic energy of working fluid at the tooth tip clearance is greater than that in the cavity. Comparison of (a) and (b) in Figure 4 reveals that the cavity pressure distribution of the optimized labyrinth seal is more uniform in (b) than in (a). The increase in cavity depth and the decrease in tooth thickness cause an increase in the filling degree of the fluid in the volume of the cavity. The improvement of pressure mean value in each cavity after optimization indicates that the kinetic pressure is effectively converted into static pressure, reducing the velocity of steam flow and making the non-stagnant steam flow out directly from next tooth less, ultimately weakening the inertia effect of the steam. Thus, the sealing effect of the seal on the working fluid is improved, and the leakage amount is reduced.

At the same time, the enlarged picture of the tip clearance at the inlet and the outlet shows that the pressure drops evenly when the working fluid flows through the seal tooth after optimization. However, the pressure of tip clearance at the inlet and the outlet "initially decreased and subsequently increased" before optimization. This shows that part of the kinetic energy of the working fluid in the accelerating process is not dissipated but reconverted into pressure energy. Consequently, the throttling effect of the sealing teeth is not obvious, and the leakage increased before optimization.

Figure 5 shows a graph of entropy of trace derived from the fixed monitoring points at the inlet before and after the optimization of the labyrinth seal. Comparison of entropy curves before and after optimization reveals that the entropy of steam shows a surging trend. However, the peak of entropy after optimization is greater than that before optimization, indicating that the working fluid flowing through the optimized seal teeth experiences greater energy loss. The two curves decreases after the peak of entropy, but the entropy of the optimized

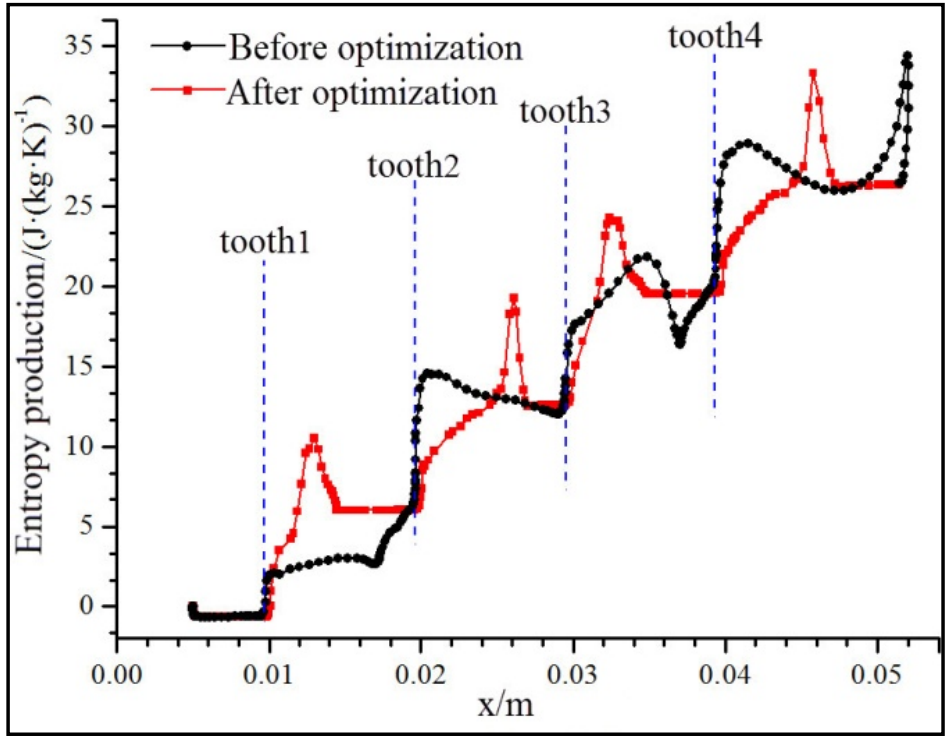

Figure 5. Entropy graph of trace before and after the optimization. 
model declines faster. Entropy changes smoothly before arriving at the next seal tooth. Then, the energy loss of the steam is reduced. The main reason of this is that the steam is stagnant, the velocity of the steam is smaller, and most of the kinetic energy is converted into pressure energy, leading to the reduction of energy dissipation. However, the reduced energy dissipation does not cause increased leakage, because the inertia effect almost disappeared due to the stagnant steam, which greatly reduces the leakage amount.

Figure 6 shows the leakage of labyrinth seal before and after optimization under different loads. The leakage amount of the labyrinth seal increases with an increase in the load regardless of optimization, but the leakage tendency of the optimized labyrinth seal increase with an increase in load is small. The leakage amount of optimized labyrinth seal is reduced by $0.466,0.567,0.812$, and 1.037 $\mathrm{kg} / \mathrm{s}$ for loads of $40 \%, 50 \%, 75 \%$, and $100 \%$, accounting for $78.85 \%, 78.75 \%$, $78.61 \%$, and $78.32 \%$ when compared with that before optimization. In conclusion, the leakage amount of the optimized labyrinth seal has the same small leakage amount under different loads.

\section{Conclusions}

The regression equation of the structure parameters and leakage amount of labyrinth seal is established by performing a quaternion quadratic regression orthogonal experiment. The equation satisfies the test of significance and not lack of fit. In this paper, the theoretical calculation results are in good accordance with the simulation results, which can meet the needs of the actual project.

The cavity depth, convex platform height, tooth thickness, and tooth tip clearance of the labyrinth seal exerts a certain influence on the sealing performance. The tip clearance is the main factor that influences the leakage amount, and leakage amount was positively correlated with the change of tip clearance. Under the influence of multiple factors, the leakage amount of the labyrinth seal has the minimum value.

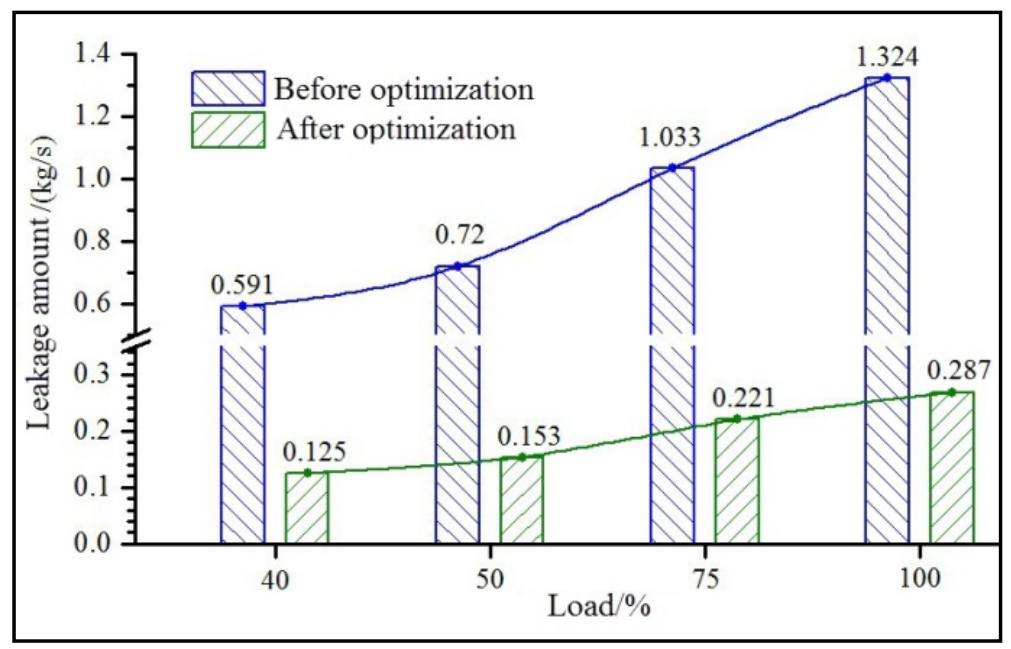

Figure 6. The leakage of labyrinth seal before and after optimization under different loads. 
After the optimization of the structure parameters of the labyrinth seal, the leakage amount of optimized labyrinth seal is reduced by approximately $78 \%$ when the optimal structure ratio is $x_{1}: x_{2}: x_{3}: x_{4}=65: 22.5: 1: 1$. The entropy increases and the peak of entropy is higher than that before optimization when steam flows through the tip clearance, enhancing the energy dissipation effect and improving the throttling effect. Moreover, the larger volume of the cavity improves the steam stagnation, and the conversion of dynamic pressure into static pressure is promoted. The inertia effect is greatly reduced, such that the optimized labyrinth seal has a decreased leakage amount under different loads.

\section{Acknowledgements}

This work was supported by National Natural Science Foundation of China (51576036).

\section{References}

[1] Jun, L.I., Yan, X., Song, L.M., Deng, Q.H., Feng, Z.P.,\& Jiang, S. K., et al. (2008)A review of sealing technologies in Turbomachinery. Thermal Turbine, 37, 141-148.

[2] Denecke, J., Färber, J., Dullenkopf, K., \& Bauer, H. J. (2008) Interdependence of Discharge Behavior, Swirl Development and Total Temperature Increase in Rotating Labyrinth Seals. ASME Turbo Expo 2008: Power for Land, Sea, and Air, Berlin, Germany, 9-13June, 2008, 1717-1724. https://doi.org/10.1115/GT2008-51429

[3] Ivanov, A. V., \& Moskvicev, A. V. (2015) Influence of Geometry on Vortex Configuration and Dimension in Lre Turbopump Labyrinth Seal. Procedia Engineering, 106, 126-131. https://doi.org/10.1016/j.proeng.2015.06.015

[4] Subramanian, S., Sekhar, A. S., \& Prasad, B. V. S. S. S. (2015) Influence of Combined Radial Location and Growth on The Leakage Performance of a Rotating Labyrinth Gas Turbine Seal. Journal of Mechanical Science and Technology, 29, 2535-2545. https://doi.org/10.1007/s12206-015-0545-8

[5] Cao L., Liu Y., Zhang Y., Li Y. (2014)Numerical Investigation of Leakage Effects Of Rub-Grooves on Labyrith Seal. Lubrication Engineering, 8-13.

[6] Zhang, W. F., Yang, J. G., Tian, Y. W., Cao, H., \& Gu, J. G. (2013) Research on the Leakage and Dynamic Characteristics of a New Kind of Radial Annular Seal and Comparisons With Labyrinth Seals. Proceedings of the Institution of Mechanical Engineers Part A Journal of Power \& Energy, 227, 261-271. https://doi.org/10.1177/0957650912474388

[7] Zhigang, L.I., Lang, J., Jun, L.I., \& Feng, Z. (2011) Experiment on Leakage Flow Characteristics of Labyrinth Seal. Journal of Xian Jiaotong University, 107, 359-361.

[8] Z. Li, J. Li, \& Z. Feng. (2010) Effects of Gap Pressure Ratio and Rotational Speed on Discharge Behavior of Labyrinth Seal. Journal of Xian Jiaotong University, 44, 1620.

[9] Bozzi, L., D’Angelo, E., Facchini, B., Micio, M., \& Soghe, R. D. (2011) Experimental Investigation on Leakage Losses and Heat Transfer in a Non-Conventional Labyrinth Seal. ASME 2011 Turbo Expo: Turbine Technical Conference and Exposition, British Columbia, Canada, 6-10 June, 2011, 955-965. https://doi.org/10.1115/gt2011-46362

[10] Jun, L.I., Qiang, L., Feng Z.P. (2006). Research on the Leakage Flow Characteristics in the Stepped Labyrinth Seal. Journal of Mechanical Engineering, 42, 165-168. 
[11] Tong, S. K., \& Cha, K. S. (2009). Comparative analysis of the influence of labyrinth seal configuration on leakage behavior. Journal of Mechanical Science and Technology, 23, 2830-2838. https://doi.org/10.1007/s12206-009-0733-5

[12] Wang, Y., Wang, L. N., \& Zhang, K. L. (2012) Numerical study of flow field and leakage characteristics of labyrinth seal for high speed gearbox. Diesel Locomotives.

[13] Yuan, H., Pidaparti, S., Wolf, M., Edlebeck, J., \& Anderson, M. (2015) Numerical Modeling of Supercritical Carbon Dioxide Flow in See-Through Labyrinth Seals. Nuclear Engineering \& Design, 293, 436-446. https://doi.org/10.1016/j.nucengdes.2015.08.016

[14] Ding, X. J., Yang, Y. L., Xiao, G. J., Luo, M. W., Zhe, L. I., \& Huang, S. H. (2006) Investigation of flow and Leakage in Labyrinth Seal. Fluid Machinery, 34, 14-18.

[15] Zhang, C. Y., Feng, Y. Z., Zhang, C. M., \&Zhang H.T. (2012) Investigation of Discharge Behavior in High Pressure Labyrinth Seal of F Class Gas Turbine. Lubrication Engineering, 37,106-108.

[16] Wang, W. Z., Liu, Y. Z., Jiang, P. N., \& Chen, H. P. (2007) Numerical Analysis of Leakage Flow through Two Labyrinth Seals. Hydrodynamics, 19, 107-112. https://doi.org/10.1016/s1001-6058(07)60035-3

[17] Zhu, J., \& Chen, W. (2014) Energy and Exergy Performance Analysis of A Marine Rotary Desiccant Air-Conditioning System Based on Orthogonal Experiment. Energy, 77, 953-962.https://doi.org/10.1016/j.energy.2014.10.014

[18] Su, L., Zhang, J., Wang, C., Zhang, Y., Li, Z., \& Yang, S., et al. (2016) Identifying Main Factors of Capacity Fading in Lithium Ion Cells Using Orthogonal Design of Experiments. Applied Energy, 163, 201-210.

https://doi.org/10.1016/j.apenergy.2015.11.014

[19] Wu, X., \& Leung, D. Y. C. (2011) Optimization of Biodiesel Production from Camelina Oil Using Orthogonal Experiment. Applied Energy, 88, 3615-3624. https://doi.org/10.1016/j.apenergy.2011.04.041

[20] Fang, X., Zhou, R., \& Gebraeel, N. (2015) An Adaptive Functional Regression-Based Prognostic Model for Applications with Missing Data. Reliability Engineering \& System Safety, 133, 266-274.https://doi.org/10.1016/j.ress.2014.08.013

[21] Subramani, S., \& Panda, R. C. (2014). Statistical Regression and Modeliing Analysis for Reverse Osmosis Desalination Process.Desalination, 351, 120-127. https://doi.org/10.1016/j.desal.2014.07.038 
Submit or recommend next manuscript to SCIRP and we will provide best service for you:

Accepting pre-submission inquiries through Email, Facebook, LinkedIn, Twitter, etc. A wide selection of journals (inclusive of 9 subjects, more than 200 journals)

Providing 24-hour high-quality service

User-friendly online submission system

Fair and swift peer-review system

Efficient typesetting and proofreading procedure

Display of the result of downloads and visits, as well as the number of cited articles Maximum dissemination of your research work

Submit your manuscript at: http://papersubmission.scirp.org/

Or contact epe@scirp.org 